\title{
LAS CONTRIBUCIONES DE BIENES RAIICES: UN IMPUESTO AL PATRIMONIO AL BORDE DE LA CONSTITUCIÓN
}

Por René González Madrid, Académico de Tributación y Contabilidad, FEN UAH.

Entre las distintas formas en que se pueden clasificar los tributos, encontramos los impuestos y las contribuciones. El impuesto se define como una cantidad de dinero que una persona - natural o jurídica - entrega al Estado, por haber incurrido en un acto jurídico que permite el nacimiento de una obligación tributaria, sin proporcionarle a la persona o contribuyente, en el momento del pago, un servicio o prestación individual. El impuesto es el más común de los tributos. En cambio, las contribuciones exigen una suma de dinero al propietario de un bien raiz frente al incremento del valor de dicha propiedad, en virtud de una obra pública. La contribución implica que el Estado realiza obras públicas que van a redundar en un mayor valor de los inmuebles, es decir, hay una contraprestación directa. Estas son razones por la cual el Estado exige el pago de contribuciones.

En nuestro país erróneamente se denomina contribución al Impuesto Territorial, gravamen que afecta a los bienes raíces; ya que no se trata en caso alguno de una contribución, es más bien un impuesto.

El Impuesto Territorial es un impuesto que grava la riqueza que las personas mantienen en forma de propiedad en bienes raices, agricolas y no agrícolas; riqueza que muy probablemente ya se vio afectada por otro tipo de impuestos, como por ejemplo, el Impuesto a la Renta o el Impuesto al Valor Agregado, que afecta las ventas de ciertos inmuebles desde el 10 de enero del año 2016.

El hecho gravado que permite el nacimiento de la obligación del pago del Impuesto Territorial, es la posesión de bienes raices, por lo tanto este es un impuesto a la propiedad. Si bien el gravamen recae en el dueño del inmueble, la Ley sobre Impuesto Territorial' también considera sujeto pasivo de la obligación fiscal al ocupante de la propiedad, ya sea usufructuario, arrendatario o mero tenedor, sin perjuicio de la responsabilidad que afecte al propietario.

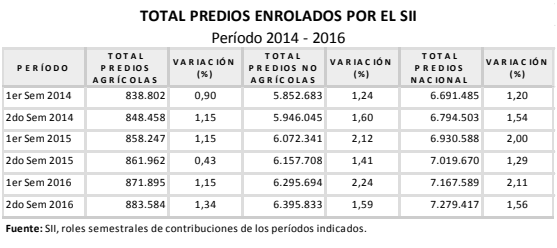

Como muestra el cuadro anterior, cada vez es mayor el aporte de bienes enrolados en el Servicio de Impuestos Internos que provienen de bienes no agricolas (88\%), debido al natural crecimiento de las grandes urbes.

La base imponible sobre la cual se aplica la tasa, la constituye el avalúo del suelo y de las edificaciones de una propiedad. El avalúo de una propiedad corresponde a un valor monetario establecido y asignado por el Servicio de Impuestos Internos a dicho bien raiz, haciendo uso de una metodologia de avaluación fiscal denominada tasación fiscal de los bienes raíces. La tasación fiscal considera el avalúo del suelo y el avalúo de la construcción, si correspondiere. Esta tasación - sin embargo no corresponde a una tasación comercial, pero igual el ente fiscalizador utiliza como referencia valores corrientes en plaza o de mercado del bien, aunque no considera todas las variables que determinan dicho valor. La tasación, por lo general, determina un valor inferior al valor corriente en plaza de una propiedad.

En el cálculo del Impuesto Territorial ${ }^{2}$, se considera el avalúo afecto a impuesto, una tasa anual, y una sobretasa de beneficio fiscal dependiendo de cada caso de avaluación.

Para los bienes raices agricolas, se aplica la tasa de 1 por ciento anual sobre el avalúo fiscal afecto. En el caso de los bienes raíces no agrícolas destinados a la habitación, se aplica la tasa de 0,98 por ciento en la parte de la base imponible que no exceda de $\$ 76.800 .583$, y 1,143 por ciento en la parte de la base imponible que exceda del monto señalado, además de una sobretasa anual de beneficio fiscal de 0,025 por ciento.

Por otra parte, los bienes raices no agricolas destinados a la habitación gozarán de un monto de avalúo exento de impuesto territorial de $\$ 21.504 .166$. La tasa anual del impuesto para los bienes raíces con destino no habitacional es de 1,2 por ciento; más una sobretasa de beneficio fiscal de 0,025 por ciento.

El impuesto territorial da origen aproximadamente al 40 por ciento de los ingresos propios municipales, siendo su principal fuente autónoma de recursos.

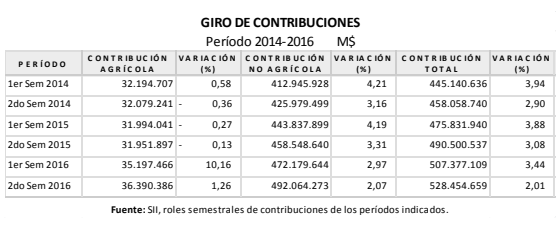

La recaudación del Impuesto Territorial se destina aproximadamente en un 40 por ciento a la municipalidad que los origina y el porcentaje restante conforma el Fondo Común Municipal, mecanismo redistributivo entre las comunas del pais en que las municipalidades con más recursos ayudan a financiar a aquellos municipios con menores recursos.

La exención en materia tributaria es una figura jurídica establecida en la propia ley mediante la cual se libera o reduce la obligación de pago de un determinado impuesto, atendiendo a razones de equidad, de política social o de incentivo económico y dirigido a un determinado grupo de personas. Si bien la exención surge de los buenos propósitos del legislador, ésta de por sí puede atentar en contra de los motivos que la genera, la equidad tributaria.

Producto de exenciones ${ }^{3}$ el Impuesto Territorial es uno de los tributos que posee las mayores mermas fiscales en la composición de su base impositiva. Es bien sabido que este tipo de discriminaciones atentan con- 
tra la equidad impositiva, tanto horizontal como vertical del impuesto; afectando su simplicidad, flexibilidad, eficiencia y capacidad recaudatoria.

La Ley sobre Impuesto Territorial contempla un importante cuerpo de exenciones que van del 100, 75 y 50 por ciento de los tributos. Considera totalmente exentas a ciertas personas jurídicas como el Fisco y Municipalidades, además de - entre otros múltiples y variados - los siguientes bienes raices:

- Establecimientos educacionales, municipales, particulares y particulares subvencionados, de educación pre básica, básica y media, reconocidos por el Ministerio de Educación, y los Seminarios asociados a un culto religioso, todos ellos, en la parte destinada exclusivamente a la educación.

- Universidades, Institutos Profesionales y Centros de Formación Técnica, reconocidos por el Ministerio de Educación, de carácter público o privado, respecto de los bienes raíces de su propiedad destinados a educación, investigación o extensión, y siempre que no produzcan renta por actividades distintas a dichos objetos.

- Bienes raíces que cumplan con las disposiciones del artículo $73^{\circ}$ de la Ley $\mathrm{N}^{\circ}$ 19.712, del Deporte. No obstante, los recintos deportivos de carácter particular sólo estarán exentos mientras mantengan convenios para el uso gratuito de sus instalaciones deportivas con colegios municipalizados o particulares subvencionados, convenios que para tal efecto deberán ser refrendados por la respectiva Dirección Provincial de Educación y establecidos en virtud del Reglamento que para estos efectos fije el Ministerio de Educación y el Instituto Nacional del Deporte.

La Ley sobre Impuesto Territorial no considera elementos como fines de lucro para eximir de este gravamen a determinados bienes raices o personas jurídicas, ya que toma en cuenta solamente el tipo de actividad desarrollada a las cuales el legislador pretende beneficiar.

Como se ha planteado anteriormente, el Impuesto Territorial es un impuesto a la propiedad, en otras palabras, un impuesto al patrimonio. El impuesto al patrimonio es uno de los gravámenes más injustos e inicuos que existen, ya que empobrece - en mayor o menor medida - al contribuyente, al tener que destinar parte de su riqueza al fisco aun cuando ese patrimonio no le haya generado rentas o beneficios pecuniarios. Este impuesto se aplica sobre riqueza que probablemente ha cumplido con tributaciones anteriores ${ }^{4}$ y que por el solo hecho de invertir en bienes raices, vuelven a ser gravadas con tributos. Si esta riqueza se hubiese invertido en otro tipo de bienes, como por ejemplo acciones o derechos sociales, no hubiesen pagado impuestos por su mera tenencia.

¿Y por qué entonces el Impuesto Territorial es tan utilizado a nivel mundial?. La razón es muy simple, es un impuesto de fácil implementación, cómoda recaudación y simple fiscalización por parte de la autoridad; lo que lo convierte en un impuesto de muy difícil evasión. Si un contribuyente no paga el Impuesto Territorial, su propiedad puede ser en un principio embargada y posteriormente rematada.

En un primer análisis, nuestra Constitución Política del Estado no admite los impuestos patrimoniales ${ }^{5}$, sin embargo, el Tribunal Constitucional ha entendido que no existe prohibición constitucional respecto de gravámenes aplicables por el único hecho de ser dueño del bien. Dicha institución ha interpretado que la expresión renta no se utiliza en un sentido técnico, sino como sinónimo de haber, expresando textualmente en el fallo: "iv) El impuesto territorial es un impuesto de tipo patrimonial, el que no sería inconstitucional toda vez que el concepto de haber y renta son similares. Por su parte, en una interpretación sistemática, el número 20 del artículo 19 y el artículo 65, ambos de la Constitución Política de la República, hablan de tributos de "cualquier naturaleza", lo que no los limita a los meramente relativos a la renta. Aún más, el mismo numeral citado, habla de tributos que graven actividades y bienes", por 10 que quedarían comprendidos los impuestos patrimoniales. Por su parte, la disposición sexta transitoria permite expresamente la supervivencia, bajo el mandato de la Constitución de 1980, de aquellos tributos de afectación preexistentes, como es el caso del impuesto territorial (considerandos trigésimo cuarto a cuadragésimo)."

El referido fallo es elocuente en cuanto a considerar que en la Constitución Política del Estado no existe una prohibición expresa y absoluta a los impuestos al patrimonio. Sin embargo esto no impide percibir un cierto grado de injusticia en nuestra carta fundamental, al aceptar la odiosa doble tributación de una misma renta, manifestada inicialmente como el impuesto al flujo de un beneficio personal - renta - y luego, como un impuesto al haber por el hecho de realizar una inversión en un bien raíz. Situación agravada por el hecho de que el referido bien raiz también pudo haber quedado afecto a un impuesto al consumo, como lo es el Impuesto al Valor Agregado.

El impuesto al patrimonio evidentemente afecta a todas las clases sociales y traducidas en un Impuesto Territorial, afecta sensiblemente a contribuyentes de ingresos medios, cuyos grandes ahorros después de años de trabajo, fueron sus fondos de pensiones y sus bienes raices. Las contribuciones, por más exenciones que existan, siguen castigando preferentemente a esta clase social. La única posibilidad de atenuar esa sensación de injusticia tributaria, es una ampliación de las garantías constitucionales que permitan no gravar nuestras propiedades con impuestos patrimoniales.

\footnotetext{
'Ley № 17.235, artículo 25.

${ }^{2}$ http://www.sii.cl/preguntas_frecuentes/bienes_raices/001_004_3848.htm

${ }^{3}$ Artículo $2^{\circ}$, del Título II de la Ley 17.235

${ }^{4}$ Impuesto a la Renta en Primera Categoria, en Global Complementario y/o Impuesto al Valor Agregado.

${ }^{5}$ Artículo 19, № 20 de la Constitución Política del Estado.

${ }^{6}$ Fallo del rol 718-2007
}

\section{Observatorio Económico}

Decano: Jorge Rodríguez Grossi

Fono Facultad: 28897366

e-mail: jrodrigu@uahurtado.cl

fen.uahurtado.cl 